\title{
19. SOME MAGNETIC PROPERTIES OF SOME LEG 37 SAMPLES
}

\author{
Aviva Brecher, Tanya Atwater, Judy Stein, and Everett Carter, \\ Department of Earth and Planetary Sciences, Massachusetts Institute of Technology, Cambridge, Massachusetts
}

\section{INTRODUCTION}

Our MIT-WHOI group received 20 partially oriented minicores and 22 unoriented samples for magnetic, petrographic, and chemical analysis. Of the former, 7 were subdivided into 3 , and 6 into 2 subsamples, to test the homogeneity of natural remanence (NRM) and magnetic susceptibility $(\chi)$, as well as the small-scale directional coherence. The latter group was comprised of petrographically or chemically interesting samples, with weathering gradients or structural inhomogeneities, whose effects on magnetic properties were of interest. To date, we have measured magnetically $\sim 70$ subsamples: the volume-normalized NRM and $\chi$ were determined for all, and AF demagnetization (typically to 400 or 500 oe levels) was carried out on 48 . Magnetic moments were measured with a Schonstedt SSM1A spinner magnetometer with a sensitivity of $\sim 10^{-6}$ emu. A Permali AF demagnetizer, with a 3-axis tumbler centered in a field-free $(<0.01$ oe) Helmbolz-coil space, was used for magnetic cleaning. We also report here on VRM acquisition on 17 samples which include all the various petrographic types encountered. We have not completed the study of saturation remanence and its relative stability of NRM, nor reduced the anisotropy of susceptibility data. At least one control subsample from each minicore was left untouched for further thermal demagnetization and thermomagnetic studies.

For the purposes of this preliminary report, thin sections of the samples were scanned and a crude petrologic description recorded. All basalts are phenocrystic. Grain size of the groundmass ranges from "fine" (FG) to "relatively coarse" (CG), the latter being as coarse as is usually found in the centers of pillows.

\section{NRM INTENSITIES AND MAGNETIC SUSCEPTIBILITIES}

Both of these parameters are of interest in identifying the source of the local magnetic anomalies at the site and in determining the relative importance of remanent and induced moments to the vertical component.

As can be seen from the NRM intensity histogram in Figure 1, the NRM of most of the samples is in the narrow range $10-50 \times 10^{-4} \mathrm{emu} / \mathrm{cm}^{3}$. Basalts with a relatively coarse grained groundmass have slightly lower NRM intensities than those with fine-grained groundmass.

The distribution of magnetic susceptibility $(\chi$ in $\mathrm{emu} / \mathrm{cm}^{3}$ ) values is shown in a histogram of Figure 1. It ranges from 8 to $323 \times 10^{-4} \mathrm{emu} / \mathrm{cm}^{3}$, most values lying in the 10 to $100 \times 10^{-4} \mathrm{emu} / \mathrm{cm}^{3}$ range. The magnetite equivalent content corresponding to this cluster is $0.2-10 \mathrm{vol} \% \mathrm{Fe}_{3} \mathrm{O}_{4} . \chi$ is not obviously related to rock type or texture.

A derived parameter, the Königsberger ratio $(Q=$ $\mathrm{NRM} / \chi \times 0.45$ ), is listed for 39 samples in Chapters 2, 3,4 , and 5 (this volume) and plotted in a histogram in Figure 1. This parameter is a measure of the relative importance of induced and remanent moments, as well as an indicator of the dominant type of carriers: coarse, multidomain versus finer (pseudo)-single domain. Forty percent of the samples have $0.1 \leq Q \leq 1$, in the multidomain range; $60 \%$ have $Q>1$, reflecting the presence of fine-grained carriers of probably stable NRM. There is a slight tendency for our basalt samples with coarse-grained groundmass to have the lower $Q$ values, reflecting coarser grained magnetic carriers. Our three gabbro samples have the lowest $Q$ values, as expected.

\section{NRM DIRECTIONS}

Measurements were made of subsamples of 19 vertically oriented minicores and 16 unoriented samples. Ten of the oriented samples were from Hole 332B and they show the same shallow inclinations that have been commonly reported for this site. Only one sample, $332 \mathrm{~B}-37-3,11-13 \mathrm{~cm}$, was consistently, significantly normal. Also in agreement with previous work, oriented samples from Sites 334 and 335 all have steep $\left(\sim 60^{\circ}\right)$ reversed inclinations. In most cases directional coherence between adjacent subsamples is fair. In the worst case (332B-3-2, 77-80 cm, the subsample with the odd direction proved to be extremely unstable during AC demagnetization.

\section{NRM DEMAGNETIZATION BEHAVIOR}

\section{Hardness Spectra}

The normalized curves of AF demagnetization of NRM display the microcoercivity spectrum for each sample and provide a measure of its NRM stability (hardness). We use as rough indices of relative NRM stability: (a) the mean destructive field, MDF: the AF level at which half of the original NRM is lost; (b) $J_{100} / \mathrm{NRM}$, i.e., the residual NRM fraction after cleaning in the 100-oe peak field (Chapters 2, 3, 4, and 5 [this volume]).

Thirty-three samples had at least one subsample cleaned in AF fields up to 400 or 500 oe. Their demagnetization curves generally fit one of three types: fast, smooth decrease (low MDF and $J_{100} / \mathrm{NRM}$ ); slow, smooth decrease (MDF high, $J_{100} / \mathrm{NRM}$ high but $<1$ ); initial increase of $5 \%$ to $10 \%$ followed by smooth decrease $\left(J \max / \mathrm{NRM}\right.$ or $\left.J_{100} / \mathrm{NRM}>1\right)$. Six samples fall into the last group, while the rest are about equally 


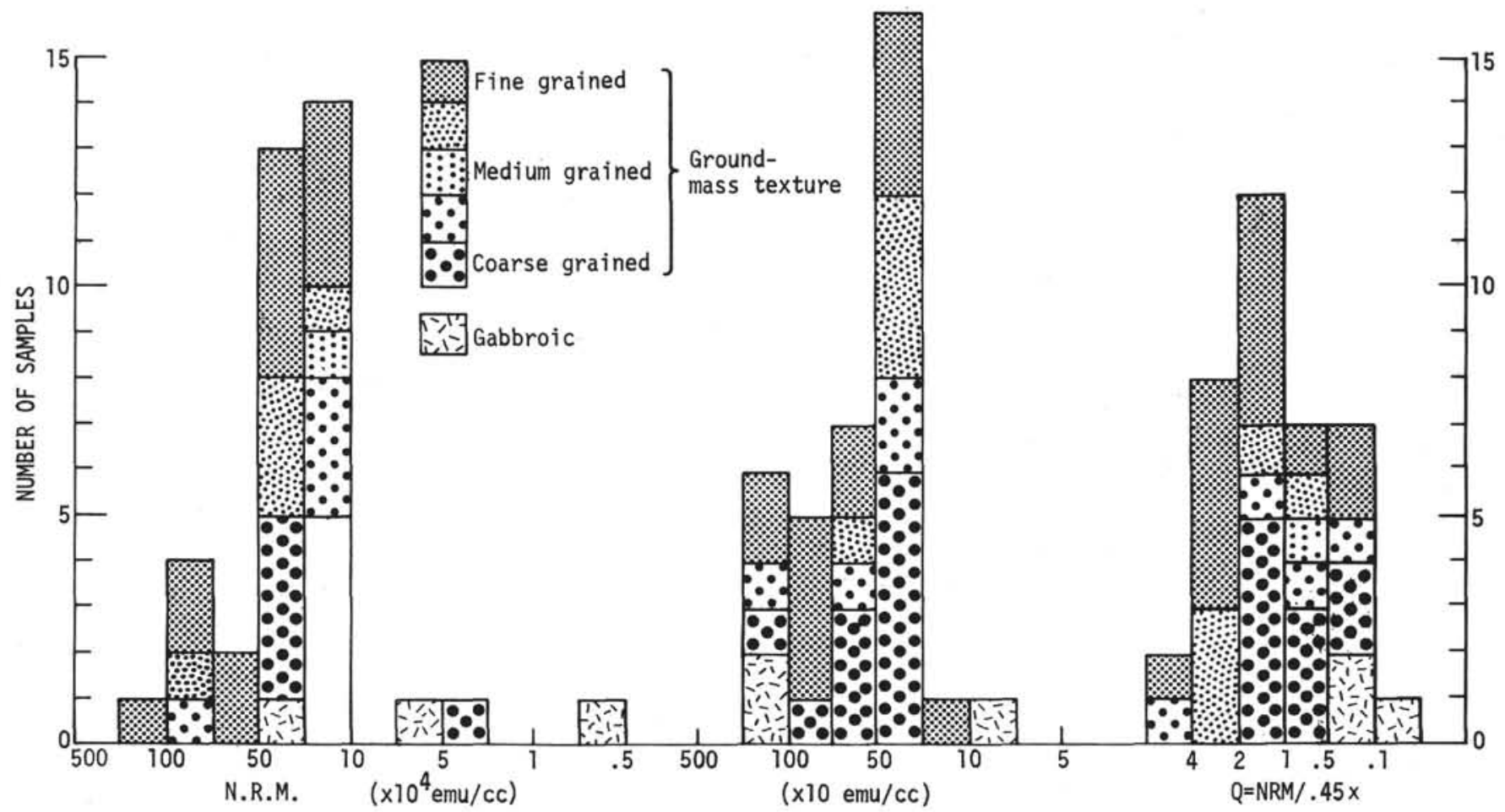

Figure 1. Histograms of NRM intensity, susceptibility, and X Königsberger ratio for various rock types. Subsamples are averaged and are plotted as a single value for the sample, unless clear alteration gradients are present. These groupings are given in Table 1. The range in groundmass texture from fine grained to relatively coarse grained is approximately that range encountered going from the edge to the center of a pillow.

divided between the first two groups. The gabbro samples all fall into the slowly decreasing group, as do all but one of the highly weathered samples. No obvious correlation with groundmass texture was observed. In one case (333A-3-1, 75-76 cm) we had two adjacent samples, one fresh and one slightly weathered. The fresh sample has a soft, antiparallel component $\left(J_{50} / \mathrm{NRM}=1.07\right)$, yet a higher MDF $(\sim 225$ oe $)$ than the weathered part (MDF $\sim 150$ oe). For two of the gabbro samples, adjacent subsamples were run and have quite different demagnetization curves, attesting to the centimeter-scale inhomogeneities in these rocks.

\section{Directional Stability}

Direction of magnetization for successive steps during demagnetization was plotted on a stereonet. Most samples have clustered directions for many steps and then begin to move, some slowly, some wildly. This breaking point usually corresponded approximately to the MDF. In Table 1, we include the amount by which the direction had shifted at the last point before the MDF, to give an idea of the tightness of the cluster. Many of the clusters are extremely tight, more than half of them having variation of $5^{\circ}$ or less below the MDF value. Only three samples (noted in the table) showed a smooth motion in some consistent direction, one became more steeply reversed, one became more steeply normal, and one changed from shallow normal to shallow reversed. The shallow inclinations found at Site 332 were as stable as the others. The only wildly unstable direction at that site was 332B-3-2, 77-80 cm (a), which was also the steepest.

\section{VISCOUS REMANENCE (VRM) ACQUISITION}

The 17 samples ( $25 \%$ of the total) whose VRM was studied (Table 2) comprise a representative crosssection of the rock types encountered in each hole (332B, 334, 335). On 3 of these, very coarse grained and therefore expected to show large VRM effects, VRM was imprinted without prior alternating field (AF) cleaning of NRM. On the others, after AF cleaning to 500 oe, VRM was acquired for time scales up to $75 \mathrm{hr}$, in a field of 5 oe, in order to enhance the VRM intensity. The viscosity coefficient, $S$ (Table'2) derived from the slope of VRM versus log $t$ (time of exposure in sec), has been corrected for earth's field $(0.45 \mathrm{oe})$ and extrapolated to the duration $\left(\tau \sim 7 \times 10^{5} \mathrm{yr}\right)$ of the current geomagnetic normal epoch, yielding the ratio $\triangle$ VRM/NRM. $S$ (in units of $10^{-4}$ ) ranges from 0.007 to 7. The relative importance of a VRM contribution to NRM is indexed by $\triangle V R M / N R M$, which ranges from $<0.01$ to nearly 1 .

\section{VRM versus Rock Type}

The coarsest grained rocks might be expected to exhibit the largest VRM, unless weathering broke up the magnetic grains into subgrains and the fine-grained basalts should have negligible soft VRM components. This holds true only roughly: the lowest $\triangle V R M / N R M$ ratios are seen in samples of moderately weathered fine grained basalts. The highest are observed in coarse and medium coarse grained basalts and a gabbro. The values of the VRM/NRM ratio are systematically low for Site 335 samples, most of which are of the 
TABLE 1

Magnetic Properties of Some Leg 37 Samples

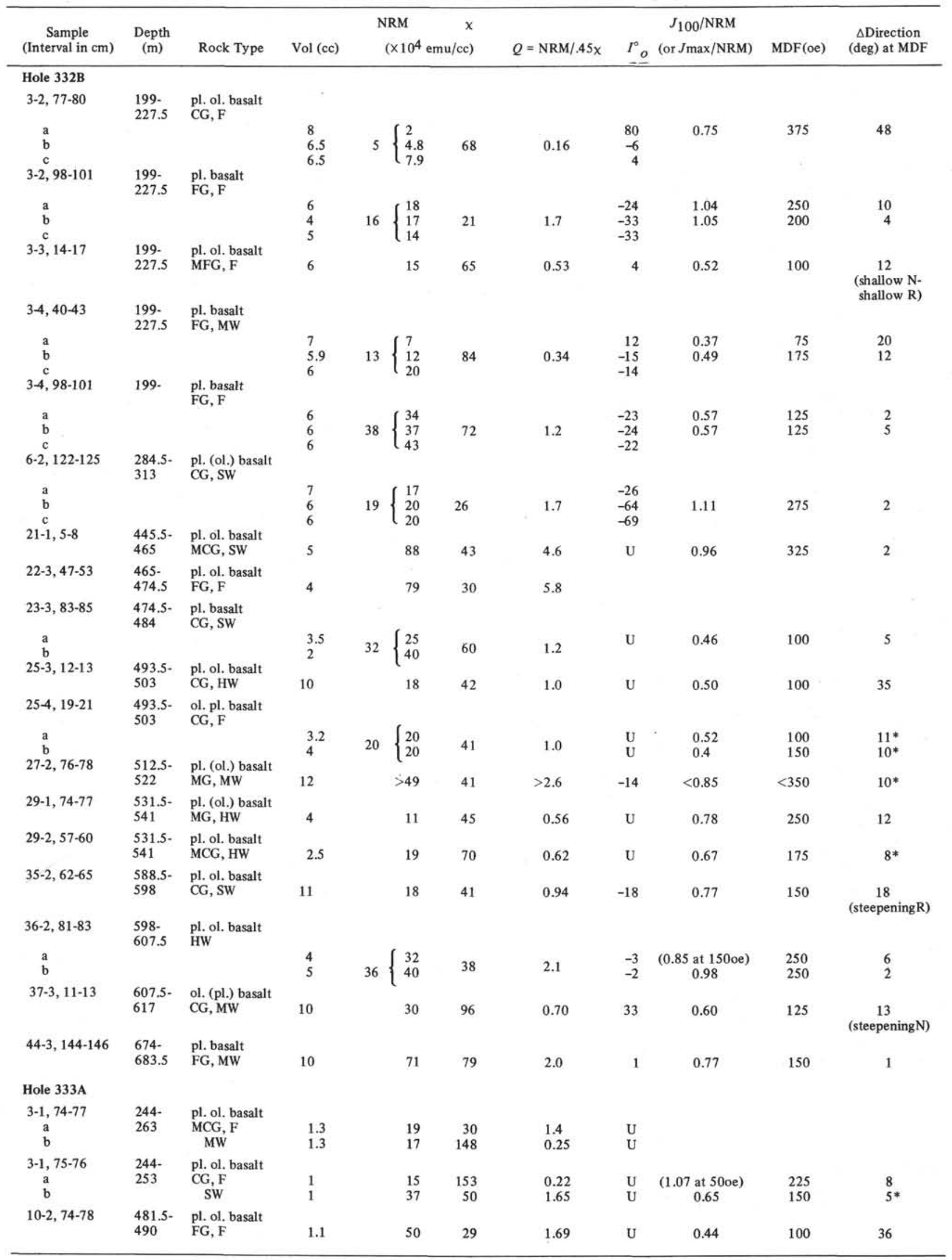


TABLE 1 - Continued

\begin{tabular}{|c|c|c|c|c|c|c|c|c|c|c|c|c|}
\hline $\begin{array}{c}\text { Sample } \\
\text { (Interval in } \mathrm{cm} \text { ) }\end{array}$ & $\begin{array}{l}\text { Depth } \\
\text { (m) }\end{array}$ & Rock Type & Vol (cc) & & $\begin{array}{l}\left(\times 10^{4} \mathrm{em}\right. \\
\end{array}$ & $\begin{array}{r}x \\
\mathrm{hu} / \mathrm{cc})\end{array}$ & & $Q=\mathrm{NRM} / .45 \mathrm{x}$ & $r_{0}$ & $\begin{array}{c}J_{100} / \mathrm{NRM} \\
\text { (or } J \max / \mathrm{NRM} \text { ) }\end{array}$ & MDF(oe) & $\begin{array}{l}\triangle \text { Direction } \\
\text { (deg) at MDF }\end{array}$ \\
\hline \multicolumn{13}{|l|}{ Site 334} \\
\hline $16-3,29-31$ & $\begin{array}{l}262.5- \\
272\end{array}$ & $\begin{array}{l}\text { pl. ol. basalt } \\
\mathrm{CG} \text {, HW }\end{array}$ & 3.6 & & 39 & 65 & & 1.3 & $\mathrm{U}$ & 0.89 & 200 & 8 \\
\hline $\begin{array}{l}19-2,17-19 \\
\mathrm{o} \\
\mathrm{m} \\
\mathrm{i}\end{array}$ & $\begin{array}{l}291- \\
300.5\end{array}$ & $\begin{array}{l}\text { pl. (ol.) basalt } \\
\text { FG, HW } \\
\text { MW } \\
\text { SW }\end{array}$ & $\begin{array}{l}0.5 \\
0.5 \\
1\end{array}$ & & $\begin{array}{l}25 \\
77 \\
37\end{array}$ & $\begin{array}{r}142 \\
99 \\
149\end{array}$ & & $\begin{array}{r}.4 \\
1.7 \\
.6\end{array}$ & $\begin{array}{l}\mathrm{U} \\
\mathrm{U}\end{array}$ & $\begin{array}{c}0.93 \\
(1.08 \text { at } 50 \mathrm{oe}) \\
1.0\end{array}$ & $\begin{array}{l}250 \\
300 \\
200\end{array}$ & $\begin{array}{l}4 * \\
2 \\
3\end{array}$ \\
\hline $\begin{array}{l}21-1,36-47 \\
\text { a } \\
\text { b }\end{array}$ & $\begin{array}{l}310- \\
319.5\end{array}$ & gabbro & $\begin{array}{l}0.65 \\
1\end{array}$ & 6.2 & $\left\{\begin{array}{l}6.8 \\
6.5\end{array}\right.$ & 8.1 & $\begin{array}{l}8.5 \\
7.7\end{array}$ & $\begin{array}{ll}.17 & .15 \\
.19\end{array}$ & $\stackrel{\mathrm{U}}{\mathrm{U}}$ & $\begin{array}{l}0.90 \\
0.98\end{array}$ & $\begin{array}{l}425 \\
275\end{array}$ & $\begin{array}{l}1 \\
4\end{array}$ \\
\hline $\begin{array}{l}22-2,34-35 \\
\text { a } \\
\text { b } \\
\text { c }\end{array}$ & $\begin{array}{l}319.5- \\
329\end{array}$ & $\begin{array}{l}\text { gabbro } \\
\text { SW }\end{array}$ & $\begin{array}{l}5 \\
4.5 \\
6\end{array}$ & 29 & $\left\{\begin{array}{l}33 \\
33 \\
20\end{array}\right.$ & 323 & & .20 & $\begin{array}{l}-65 \\
-63 \\
-64\end{array}$ & $\begin{array}{l}0.95 \\
0.81\end{array}$ & $\begin{array}{r}>400 \\
175\end{array}$ & $\begin{array}{l}2 \\
2\end{array}$ \\
\hline $\begin{array}{l}27-1,38-50 \\
\quad \text { a } \\
\text { b } \\
\text { c }\end{array}$ & $\begin{array}{l}367- \\
376.5\end{array}$ & $\begin{array}{l}\text { gabbro } \\
\text { MW }\end{array}$ & $\begin{array}{l}6 \\
5.5 \\
5\end{array}$ & 7.4 & $\left\{\begin{array}{l}8.4 \\
6.3\end{array}\right.$ & 16 & & .10 & $\begin{array}{l}\mathrm{U} \\
\mathrm{U} \\
\mathrm{U}\end{array}$ & (1.03 at $50 \mathrm{oe})$ & 150 & 3 \\
\hline \multicolumn{13}{|l|}{ Site 335} \\
\hline $8-2,94-96$ & $\begin{array}{l}476.5- \\
486\end{array}$ & $\begin{array}{l}\text { pl. basalt } \\
\text { FG, SW }\end{array}$ & 8 & & 72 & 5 & 0 & 3.2 & -57 & 0.83 & $>400$ & $5 *$ \\
\hline $8-4,20-21$ & $\begin{array}{l}476.5- \\
486\end{array}$ & $\begin{array}{l}\text { pl. ol. basalt } \\
\text { MG, MW }\end{array}$ & 8 & & 35 & 3. & 5 & 2.2 & -61 & 0.93 & 275 & 5 \\
\hline $10-3,100-102$ & $\begin{array}{l}495.5- \\
505\end{array}$ & $\begin{array}{l}\text { pl. basalt } \\
\text { FG, HW }\end{array}$ & 11 & & 12.5 & & 9.7 & 2.9 & -56 & 1.0 & $>500$ & 3 \\
\hline $\begin{array}{l}10-6,4-6 \\
\text { a } \\
\text { b }\end{array}$ & $\begin{array}{l}495.5- \\
505\end{array}$ & $\begin{array}{l}\text { pl. (ol.) basalt } \\
\text { MG, SW }\end{array}$ & $\begin{array}{c}11 \\
4.9\end{array}$ & 46 & $\left\{\begin{array}{l}46 \\
45\end{array}\right.$ & 49 & $\begin{array}{l}36 \\
62\end{array}$ & $\begin{array}{ll}2.1 & 2.9 \\
1.6\end{array}$ & $\begin{array}{l}-58 \\
-58\end{array}$ & 0.96 & 325 & 8 \\
\hline $\begin{array}{l}11-1,62-64 \\
\text { a } \\
\text { b }\end{array}$ & $\begin{array}{l}505- \\
514.5\end{array}$ & $\begin{array}{l}\text { pl. basalt } \\
\text { FG, MW }\end{array}$ & $\begin{array}{c}11 \\
5.1\end{array}$ & 39 & $\begin{array}{l}44 \\
34\end{array}$ & 25 & $\begin{array}{l}24 \\
26\end{array}$ & $\begin{array}{ll}3.4 \quad 4.0 \\
2.8\end{array}$ & $\begin{array}{l}-67 \\
-65\end{array}$ & 0.95 & $>000$ & \\
\hline $12-2,139-141$ & $\begin{array}{l}514.5- \\
524\end{array}$ & $\begin{array}{l}\text { pl. basalt } \\
\text { FG, MW }\end{array}$ & 11 & & 22 & 2 & & 1.7 & -59 & 1.04 & 8 & \\
\hline
\end{tabular}

Note: pl. $=$ plagioclase phenocrysts $;$ ol. $=$ olivine phenocrysts $; \mathrm{FG}=$ fine grained groundmass; $\mathrm{MG}=$ medium grained groundmass; $\mathrm{CG}=$ coarse grained groundmass; $\mathrm{F}=$ fresh; $\mathrm{SW}=$ slightly weathered; $\mathrm{MW}=$ moderately weathered; $\mathrm{HW}=$ highly weathered; $\mathrm{NRM}=$ natural remanent magnetization; $\mathrm{x}=$ susceptibility; $Q=$ Königsberger ratio $I^{\circ}$ o inclination of NRM; $J_{100} / \mathrm{NRM}=$ residual NRM fraction after 100 -oe AF cleaning; $J$ max $=$ maximum intensity reached during $\mathrm{AF}$ demagnetization; $\mathrm{MDF}=$ mean destructive field; $\mathrm{U}=$ unoriented sample. All others were partially (vertically) oriented; *Denotes angular shift with respect to 50-oe demag. step instead of NRM.

TABLE 2

VRM in Leg 37 Samples

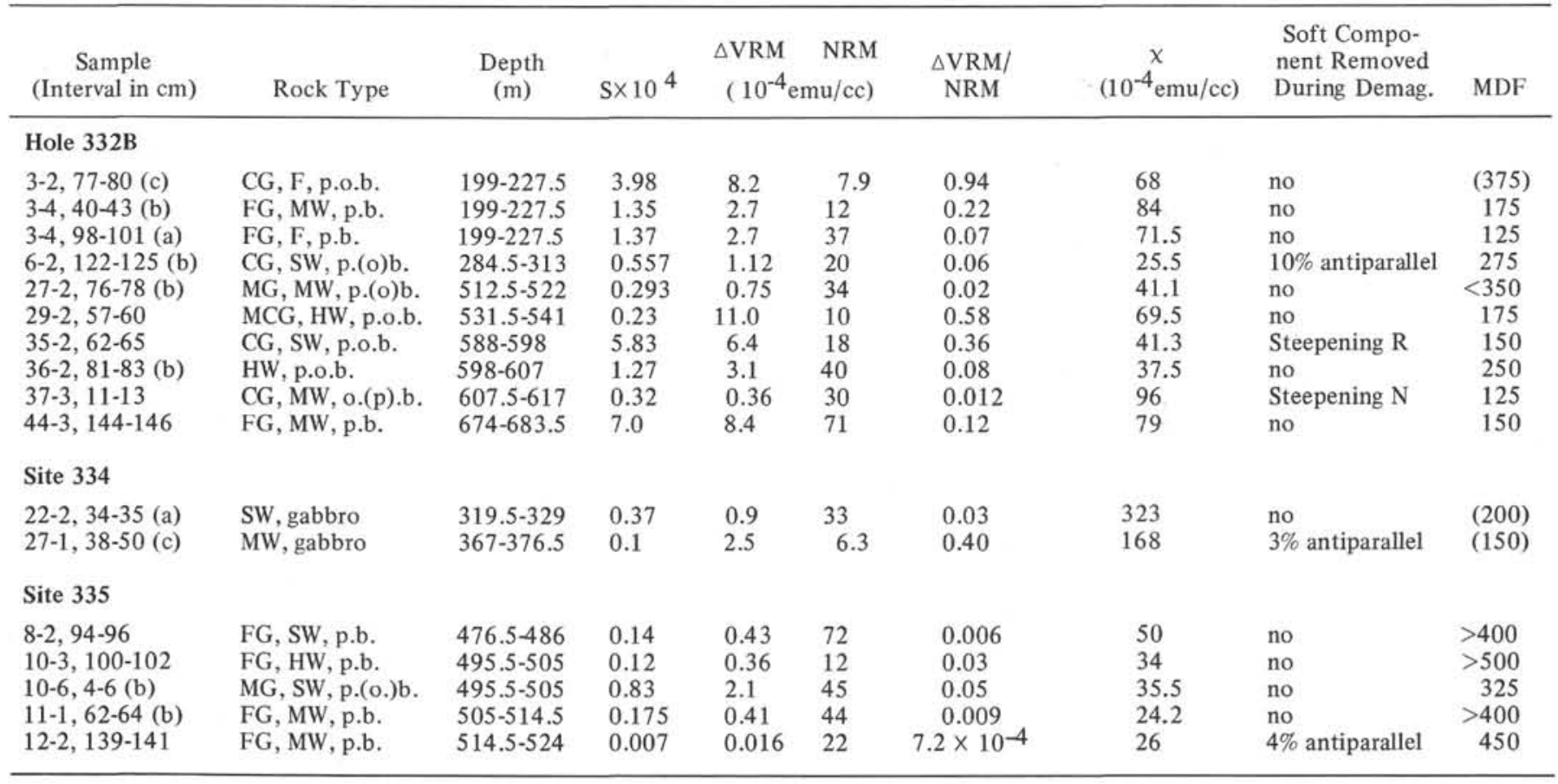


weathered-FG basalt type. A $0.01-1$ spread of ratio values is seen in a suite of 332B samples spanning the hole depth. There is no apparent correlation of VRM with sample depth.

\section{VRM versus NRM Stability}

It could be expected that a soft NRM component and/or a change in polarity upon AF cleaning are attributable to VRM. The values of the VRM coefficient $S$ are generally low, as are $\triangle \mathrm{VRM} / \mathrm{NRM}$ ratios, for rocks whose NRM is hard and of stable polarity. Also, some of the larger values of $\triangle V R M / N R M$ are found in rocks which have some indication of a soft compo- nent during demagnetization. However, this is not true for the two highest values. The NRM median destructive fields (MDF) for the samples whose VRM was studied range broadly from 75 to $>500$ oe. A high MDF ( $>200$ oe) almost always corresponded to a low $\triangle \mathrm{VRM} / \mathrm{NRM}$, but not vice-versa.

\section{VRM versus $\chi$}

It might also be expected that a large $\chi$ will correspond to larger induced and viscous moments. Nevertheless, no correlation of $\chi$ with susceptibility to VRM acquisition was apparent: samples with high $\chi$ have very low $\triangle \mathrm{VRM} / \mathrm{NRM}$ ratios. 